\title{
IGFBP-2 and aging: a 20-year longitudinal study on IGFBP-2, IGF-I, BMI, insulin sensitivity and mortality in an aging population
}

\author{
Annewieke W van den Beld ${ }^{1}, 2$, Olga D Carlson ${ }^{3}$, Maire E Doyle ${ }^{3}$, Dimitris Rizopoulos ${ }^{4}$, Luigi Ferrucci ${ }^{3}$, \\ Aart Jan van der Lely ${ }^{2}$ and Josephine M Egan ${ }^{3}$ \\ ${ }^{1}$ Department of Internal Medicine, Groene Hart Hospital, Gouda, The Netherlands, ${ }^{2}$ Department of Internal \\ Medicine, Erasmus Medical Center, Rotterdam, The Netherlands, ${ }^{3}$ Laboratory of Clinical Investigation, National \\ Institute on Aging, Baltimore, Maryland, USA, and ${ }^{4}$ Department of Biostatistics, Erasmus Medical Center, Rotterdam, \\ The Netherlands
}

Correspondence

should be addressed

to $A$ W van den Beld

Email

a.vandenbeld@erasmusmc.nl

\begin{abstract}
Objective: Insulin-like growth factor-binding protein-2 (IGFBP-2) concentrations are low in subjects with metabolic syndrome and type 2 diabetes. Intriguingly, recent studies have demonstrated an association between high IGFBP-2 concentrations and increased mortality not only in populations with certain types of cancer, but also in relatively healthy populations. We evaluated the role of IGFBP-2 in relation to BMI and mortality.

Design and Participants: BMI, insulin sensitivity, insulin-like growth factor 1 (IGF-I) and IGFBP-2 were assessed repeatedly in 539 participants of the Baltimore Longitudinal Study of Aging around the ages of 55, 65 and 75 years. Results: IGFBP-2 concentrations positively correlated with insulin sensitivity and inversely with BMI, both at baseline and follow-up. Independent of IGF-I, sex, BMI and insulin sensitivity, circulating IGFBP-2 levels positively correlated with age $(P<0.001)$. Changes over time in BMI were associated with an inverse correlation in IGFBP-2 concentrations. Furthermore, we found indications of a relationship between low baseline IGFBP-2 levels and mortality. Remarkably, after adjustment for insulin sensitivity, the opposite association was found, as a unit increase of log(IGFBP2) was associated with an increase in the log hazard by $1.43(95 \% \mathrm{Cl}$ : $0.3-2.6)$. This accounted for both baseline $(P=0.02)$ as well as serial $(P<0.001)$ measurements of IGFBP2. Finally, in this longitudinal study, we found that IGF-I concentrations increased with age $(0.82 \pm 0.2(\mu \mathrm{g} / \mathrm{L}) /$ year, $P<0.001)$.

Conclusion: This is the first study investigating the relationship between IGFBP-2 levels and age in a longitudinal setting. Serum IGFBP-2 levels increase with age after the age of 50 years and evolve in parallel with insulin sensitivity. IGFBP-2 may therefore be a potential marker for insulin sensitivity. We further show that IGFBP-2 levels can predict mortality in this aging population. However, its predictive value for mortality can only be interpreted in relation to insulin sensitivity. After adjustment for insulin sensitivity, high IGFBP-2 levels are predictive of increased mortality.
\end{abstract}

\section{Introduction}

Most studies demonstrate that growth hormone (GH) and insulin-like growth factor 1 (IGF-I) concentrations decrease with age $(1,2)$. Available evidence suggests that age-related decline in $\mathrm{GH}$ release is a protective mechanism that reduces the risk of age-related diseases, primarily cancer and type 2 diabetes (3). In the last decade, many studies have focused on insulin-like growth factorbinding protein (IGFBP)-2, the second most abundant IGF-binding protein. The IGFBPs regulate the ability of IGFs to activate the IGF-I receptors and some of them (c) 2019 European Society of Endocrinology Printed in Great Britain
Published by Bioscientifica Ltd. 
have IGF-independent actions through translocation into the cell. In the nucleus, IGFBP-2 activates the expression of several genes involved in tumorigenesis (4). The precise roles, if any, of IGFBP-2 in health and disease are not fully elucidated. IGFBP-2 concentrations are strongly inversely associated with BMI $(5,6,7)$ and are low in subjects with metabolic syndrome $(8,9)$ or type 2 diabetes mellitus (7). In contrast, IGFBP-2 concentrations are high in subjects with anorexia nervosa (10). In addition, IGFBP-2 overexpression prevents obesity and diabetes in experimental animal models $(5,6)$. Apart from its possible beneficial effects on body composition, IGFBP-2 is commonly expressed in a range of human cancers. It is still unknown, however, whether IGFBP-2 is tumor suppressive or oncogenic (reviewed by Pickard and McCance (11)). Several studies have demonstrated that high IGFBP-2 concentrations were associated with an increased mortality in patients with colorectal, ovarian and breast cancers $(12,13,14)$. In addition, in two relatively healthy elderly populations, high IGFBP-2 concentrations were associated with an increased risk of mortality. We demonstrated that high IGFBP-2 concentrations were related to an increased risk of 8-year all-cause mortality in a population of 403 older men (mean age, 78 years) (9). Also, Hu et al. (15) reported that in a healthy population of 625 men and women older than 70 years, higher IGFBP-2 concentrations were associated with an increased risk of 6-year all-cause mortality.

These findings together led to the hypothesis that apart from its potential association with cancer, IGFBP-2 may be a marker of nutritional status and may play a role in the process of anorexia of aging. It may even be the case that IGFBP-2 levels increase before weight loss occurs during aging. To test this hypothesis, we investigated a group of men and women from the Baltimore Longitudinal Study of Aging around the ages of 55, 65 and 75 years. The first objective of the study was to investigate whether an increase in IGFBP-2 levels is associated with changes in BMI in a longitudinal setting during aging. The second objective of this study was to investigate if higher IGFBP-2 concentrations are related to an increased mortality risk, and if so, whether this association is cancer related.

\section{Patients and methods}

\section{Study population}

The Baltimore Longitudinal Study of Aging (BLSA) is an ongoing longitudinal study carried out with community-dwelling volunteers with above average education, income and access to medical care as well as increased general health consciousness. A general description of the sample population, the recruitment criteria and implementation of the BLSA, have been previously reported $(16,17)$. The BLSA protocol is approved by National Institutes of Health (NIH)/National Institute of environmental Health Services International Review Board (NIEHS IRB) which complies with the principles stated in the Declaration of Helsinki. All subjects signed an IRB-approved informed consent.

The objective was to investigate the hormonal parameters of volunteers over the course of at least 10 years, but preferably over 20 years. Therefore, a subset of volunteers of the BLSA was identified who visited the study center starting around the age of 50 years and continuing through their 60s and 70s. The present study was finally conducted in a subset of 539 subjects (324 men). Serum IGFBP-2 and IGF-I levels were measured at each of these consecutive visits. Body height and weight were objectively measured, and BMI was calculated by dividing body weight in kilograms by the square of height in meters $\left(\mathrm{kg} / \mathrm{m}^{2}\right)$.

\section{Mortality}

Mortality data were collected by intermittent telephone follow-up of inactive participants and correspondence with participants and their relatives. Every year, regular searches of the National Death Index were conducted to ascertain the vital status of the participants. For deceased BLSA subjects, the cause of death was determined by the consensus of three physicians reviewing all available information, including death certificates, letters from physicians and families, medical records and autopsy reports. The cause of death was classified as 'cardiovascular', 'cancer', 'other' or 'unknown'.

\section{Laboratory measures}

Blood samples were obtained from participants between 07:00 and 09:30 h after a 12-h fast.

A modified oral glucose tolerance test (OGTT) was performed on the participants. Fasting plasma was collected at baseline ( 0 min), after which subjects drank $75 \mathrm{~g}$ glucose in $300 \mathrm{~mL}$ of solution (SunDex; Fisherbrand, Pittsburgh, PA, USA), and blood samples were drawn at $5,10,15,20,40,60,80,100$ and $120 \mathrm{~min}(2 \mathrm{~h})$ after oral administration (18). 
Blood was centrifuged, and plasma and serum were stored in aliquots at $-80^{\circ} \mathrm{C}$. All hormones and biomedical assays were performed in the Laboratory of Clinical Investigation, National Institute on Aging, Baltimore, MD, USA.

Fasting serum IGF-I was measured by human IGF-I Quantikine ELISA (R\&D Systems). Intra- and inter-assay precision were in the range $3.5-4.3 \%$ and $7.5-8.3 \%$ accordingly. The minimum detectable IGF-I levels in serum ranges from 0.7 to $5.6 \mu \mathrm{g} / \mathrm{L}$. No significant cross-reactivity or interference was observed by the manufacturer.

Fasting serum IGFBP-2 was measured by IGFBP-2 ELISA (Alpco, Salem, NH, USA): this assay is specific for human IGFBP-2. Importantly, there was no cross-reactivity with IGFBP-1 and IGFBP-3. The minimum detectable amount of IGFBP-2 in serum by this assay is $4.2 \mu \mathrm{g} / \mathrm{L}$. The interand intra-assay coefficients of variability are below $10 \%$.

Plasma insulin was measured for all time points of the OGTT using an insulin ELISA (Mercodia Inc, Uppsala, Sweden). Within-assay precision is $2.8-4.0 \%$, and between-assay precision is $2.6-3.6 \%$. The detection limit is $1 \mathrm{mIU} / \mathrm{L}$ calculated as two standard deviations above the Calibrator 0. Conversion factor: $1 \mu \mathrm{g} / \mathrm{L}=29 \mathrm{mIU} / \mathrm{L}$; $1 \mathrm{mIU} / \mathrm{L}=6.0 \mathrm{pmol} / \mathrm{L}$.

\section{Insulin sensitivity index}

Originally proposed by Matsuda and DeFronzo, insulin sensitivity index-Matsuda (ISI(Matsuda)) is a wholebody ISI that reflects a composite estimate of hepatic and muscle insulin sensitivity (19). This index is calculated from plasma glucose $(\mathrm{mg} / \mathrm{dL})$ and insulin (mIU/L) concentrations in fasting state and during OGTT.

The formula for the Matsuda index is: $10000 / \sqrt{ } G 0 \times \mathrm{I} 0 \times G$ mean $\times$ Imean, where $10000 \quad-$ simplifying constant to get numbers from 0 to $12, \sqrt{ }$ - correction of the nonlinear values distribution, G0 - fasting plasma glucose concentration (mg/dL), I0 fasting plasma insulin concentration (mIU/L), Gmean mean plasma glucose concentration during OGTT (mg/ $\mathrm{dL}$ ), from 0 to $120 \mathrm{~min}$ and mean - mean plasma insulin concentration during OGTT (mIU/L), from 0 to $120 \mathrm{~min}$. Normal range is 2.7-9.6.

\section{Statistical analysis}

In this study, we analyzed data from 539 elderly patients to explore how serial measurements of the biomarker IGFBP2 evolve with time, and whether IGFBP2 levels are associated with the risk for death. To assess changes in
IGFBP2 and BMI levels over time while accounting for the correlation between repeated follow-up measurements in each patient, we utilized the framework of linear mixed-effects models (20). For both the fixed- and random-effects parts of the model, we tested for possible nonlinear evolutions, while also correcting for age and gender. Residual plots were used to validate the model's assumption, which led to the use of the logarithmic transformation with base 2 for the IGFBP2 (log2(BP2)) values for these analyses. To investigate the association between the serial IGFBP2 measurements and the risk for death and because IGFBP2 represents an endogenous timedependent covariate process, we utilized the framework of joint models for longitudinal and survival data (21). These models combine the aforementioned linear mixedeffects model with a Cox regression model in order to measure the strength of the association between the two outcomes. The open source program $\mathrm{R}$ was used for all statistical computing and graphical outputs ( $\mathrm{R}$ version 3.2.0 (2015-04-16)).

To investigate the association between the evolution of IGFBP-2 and BMI with age, a bivariate linear mixed model was fitted treating IGFBP-2 and BMI as outcomes. In both the fixed- and random-effects structure, we included different intercepts and linear time effects per outcome. The four random effects were assumed to be correlated, while the two error terms were assumed to be independent. The estimated correlation between the evolution of IGFBP-2 and BMI was captured by the corresponding element of the variance-covariance matrix of the random effects. To investigate whether the baseline IGFBP-2 measurement was predictive for the future profile of BMI, we included in the linear mixed model the main and interaction effects of time with the baseline IGFBP-2 measurements. All analyses were corrected for sex.

\section{Results}

Baseline characteristics are shown in Table 1.

\section{Serial IGFBP-2 measurements}

IGFBP-2 and BMI

We observed that both BMI and IGFBP-2 are associated with age, with every year increase in age resulting in a $0.05 \pm 0.01 \mathrm{~kg} / \mathrm{m}^{2}, P<0.0001$ increase in BMI and a $0.04 \pm 0.005, P<0.0001$ increase in $\log 2(\mathrm{BP} 2)$. Patients had on average 3.1 measurements (s.D. 1.5 measurements). 
Table 1 Baseline characteristics according to age at inclusion in a subset of participants of the Baltimore Longitudinal Study of Aging. Data are presented as mean (s.D.) or mean (95\% CI).

\begin{tabular}{|c|c|c|c|}
\hline & \multicolumn{3}{|c|}{ Age at inclusion between } \\
\hline & $50-60$ years & $60-70$ years & $70-80$ years \\
\hline Number of measurements at follow-up & $3.6(1.37)$ & $2.1(1.2)$ & $1.6(0.7)$ \\
\hline $\mathrm{BMI}\left(\mathrm{kg} / \mathrm{m}^{2}\right)$ & $27(26.5-27.4)$ & $27.2(26.3-28.1)$ & $26.6(25.2-28)$ \\
\hline Serum IGF-I ( $\mu \mathrm{g} / \mathrm{L})$ & $80.8(74-87.5)$ & 87.2 (77.7-96.7) & $106.8(91.4-122.2)$ \\
\hline Serum IGFBP-2 ( $\mu \mathrm{g} / \mathrm{L})$ & $295.6(279.4-311.8)$ & $347.2(315.4-379)$ & $402(346.6-457.5)$ \\
\hline Insulin sensitivity index & $17.1(7.9-26.4)$ & $10.6(4.5-16.7)$ & $7.8(2-13.6)$ \\
\hline
\end{tabular}

IGF-I, insulin-like growth factor 1; IGFBP-2, insulin-like growth factor binding protein-2.

IGFBP-2 and BMI were inversely related to each other (age adjusted) with every unit increase in BMI resulting in a $-0.06 \pm 0.007, P<0.0001$ decrease in $\log 2(\mathrm{BP} 2)$. The association with age remained significant for both BMI and IGFBP-2 after adjustment for each other.

\section{IGFBP-2 and its association with IGF-I}

Subsequently, we also tested for the effect of the biomarker IGF-I in the longitudinal evolutions of $\log 2$ (BP2). Due to missing values in IGF-I in this analysis 304 patients were included. We observed that IGF-I is positively correlated with $\log 2$ (BP2) with a unit increase of IGF-I at any time point resulting in a 0.002 (95\% CI: 9e-04-0.003) increase in $\log 2$ (BP2). IGF-I concentrations increased in this population with every year increase in age resulting in $0.82 \pm 0.2 \mu \mathrm{g} / \mathrm{L}, P<0.0001$ increase in IGF-I (sex, BMI and IGFBP-2 adjusted).

\section{IGFBP-2 and its association with ISI}

ISI decreased with age, with every year increase in age resulting in a 0.24 (SE 0.10$)$ point decrease in ISI $(P=0.02)$. We tested for the effect of the ISI in the longitudinal evolutions of $\log 2$ (BP2). Due to missing values in these variables, 244 patients were included in this analysis. We observed that insulin sensitivity is positively correlated with $\log 2$ (BP2) with a unit increase of ISI at any time point resulting in a $0.012 \pm 0.003(P=0.0001)$ increase in $\log 2(\mathrm{BP} 2)$ (Table 2$)$.

\section{Association between evolution of IGFBP-2 and BMI}

We investigated the association between the evolution of IGFBP-2 and BMI. The estimated correlation between the evolution of IGFBP-2 and BMI was found to be -0.64 (95\% CI, -0.75 to -0.49 ). This means that IGFBP-2 and BMI both significantly change over time in opposite directions.

We investigated whether the baseline IGFBP-2 measurement was predictive for the future profile of BMI.
The interaction between the time effect and the baseline IGFBP-2 measurement was not significant, implying that no evidence of an association was found between the evolution of BMI and the baseline levels of IGFBP-2. The main effect was significant implying that for each unit increase of $\log 2(\mathrm{BP} 2)$ at baseline, the BMI decreased by $2.83 \pm 0.28, P<0.001$, but this decrease remained constant during follow-up (time:base_log2BP2: $B=-0.02 \pm 0.01$, $P=0.13$ ) (i.e., because the interaction effect was not significant). These data show that IGFBP-2 and BMI are strongly correlated during follow-up, but that IGFBP-2 is not predictive of the course of BMI.

\section{Baseline and serial IGFBP2 measurements and risk of death}

During 20 years of follow-up, there were $176(32.7 \%)$ deaths, with $29(6.2 \%)$ due to cardiovascular disease (CVD)-related causes, 29 (6.2\%) due to cancer and $46(9.9 \%)$ due to other causes.

Baseline and serial IGFBP-2 measurements and risk of death from all causes

We have found evidence of a relationship between the baseline IGFBP-2 and the risk for death, age, sex and BMI adjusted, with a unit increase of $\log 2(\mathrm{BP} 2)$ decreases the

Table 2 Associations of $\log 2(\mathrm{BP} 2)$ with age, sex, BMI and insulin sensitivity among the subset of participants of the Baltimore Longitudinal Study of Aging.

\begin{tabular}{|c|c|c|c|c|}
\hline & $\begin{array}{c}\text { Estimate of } \\
\text { the coefficient }\end{array}$ & S.E. & t-value & $P$ value \\
\hline Intercept & 5.21 & 1.818 & 2.865 & 0.0045 \\
\hline Time & -0.02896 & 0.03142 & -0.9217 & 0.36 \\
\hline Age (years) & 0.07251 & 0.03196 & 2.269 & 0.03 \\
\hline Sex (M) & -0.0351 & 0.07514 & -0.4671 & 0.64 \\
\hline $\mathrm{BMI}\left(\mathrm{kg} / \mathrm{m}^{2}\right)$ & -0.05681 & 0.00746 & -7.615 & $<0.0001$ \\
\hline ISI & 0.01201 & 0.003054 & 3.934 & 0.0002 \\
\hline
\end{tabular}

ISI, insulin sensitivity index; S.E., standard error 
log hazard by $0.29 \pm 0.13, P=0.02$ ( $95 \% \mathrm{CI}, 0.5-0.0)$. This means that lower baseline IGFBP- 2 concentrations are associated with an increased risk of mortality. However, we hypothesized that this relationship might be influenced by insulin sensitivity, since subjects with lower IGFBP-2 concentrations have lower insulin sensitivity. Indeed, after additional adjustment for insulin sensitivity, we observed an inverse relationship between baseline IGFBP-2 and mortality risk, with a unit increase of $\log 2$ (BP2) increasing the log hazard by $1.43 \pm 0.59, P=0.02$ (95\% CI, 0.3-2.6). This implies that in subjects with the same insulin sensitivity, higher baseline IGFBP-2 concentrations are associated with an increased risk of all-cause mortality. Insulin sensitivity itself was not associated with mortality, after adjustment for sex, BMI and IGFBP-2. This analysis is however less reliable due to missing data.

We continued with the joint modeling analysis and postulated that at any follow-up time point, the level of IGFBP-2 is associated with the hazard at the same time point. Before adjustment for insulin sensitivity, we did not observe any evidence of a relationship between serial IGFBP-2 and the risk for death. However, after additional adjustment for ISI, we did observe a significant relationship between higher IGFBP-2 concentrations in serial measurements and an increased risk for death, with a unit increase of $\log 2(\mathrm{BP} 2)$ increasing the $\log$ hazard by 1.19 (95\% CI, 0.70-1.63, $P<0.001$ ).

Baseline and serial IGFBP2 measurements and risk of death from cardiovascular disease and risk of death from cancer, age, sex and BMI adjusted

We observed evidence of an inverse relationship between baseline IGFBP-2 and the risk for death from CVD, with a unit increase of $\log 2$ (BP2) decreasing the log hazard by 0.61 (95\% CI, 1.2-0.0). We have not found any evidence of a relationship between serial IGFBP2 and the risk for death from CVD. Due to insufficient data, it was not possible to adjust for ISI in these associations. Neither baseline nor serial IGFBP-2 measurements showed any correlation with the risk for death from cancer.

\section{Baseline and serial BMI measurements and risk of all events}

We have found evidence of a relationship between the baseline BMI and the risk for death, with a unit increase of BMI increasing the log hazard by 0.07 (95\% CI, 0.0-0.1, $P<0.001)$. This relation was, however, no longer present after adjustment for insulin sensitivity, with a unit increase of BMI increasing the log hazard by 0.1 (95\% CI,
$0-0.2, P=0.11$ ). We also found evidence of a relationship between serial BMI and the risk for death, with a unit increase of BMI increasing the log hazard by 0.04 (95\% CI, 0.0-0.1, $P=0.01$ ). However, after adjustment for insulin sensitivity (ISI), this relation was no longer present. Neither baseline nor serial IGFBP-2 measurements showed any correlations with the risk for death from CVD or with the risk for cancer death.

\section{Discussion}

In this longitudinal study of participants of the BLSA between the age of 50 and 80 years, we observed that IGFBP-2 concentrations increase with age, when corrected for sex, BMI, IGF-I and insulin sensitivity. Serum IGFBP-2 concentrations are strongly and inversely related with BMI and positively correlated with insulin sensitivity. IGFBP-2 and BMI change significantly over time in opposing directions. Serum IGFBP-2 concentrations, however, do not seem to predict the course of the BMI. Remarkably, mean serum IGF-I concentrations also increase with age in this population. Low IGFBP-2 concentrations at baseline were associated with an increased all-cause and CVD-related mortality. However, since low IGFBP-2 concentrations are also associated with worsening insulin sensitivity, we repeated the analyses adjusting for insulin sensitivity. Then, the opposite association was found; high baseline and serial IGFBP2 measurements were associated with an increase in mortality. These findings are in agreement with the present concept of the functional role of IGFBP-2.

IGFBP-2 is the second most abundant IGFBP and concentrations are negatively regulated by GH; that is, they are high in GH deficiency, suppressed after administration of GH in both non-deficient and GH-deficient humans, and reduced in acromegaly $(22,23)$. Following IGF-I administration to GH-deficient humans or patients with diabetes, there is a three- to four-fold increase in IGFBP-2 (23). Insulin and leptin upregulate IGFBP-2 expression (6, $24,25,26)$. In addition, dietary factors influence IGFBP-2 concentrations. Higher protein intake is associated with a decrease in serum IGFBP-2 concentrations, and there is some evidence of an inverse association with dairy protein and calcium intake $(27,28)$.

In mammals, IGFBP-2 is expressed at high levels in embryonic tissues. It decreases drastically after birth until puberty, after which it gradually increases again, especially after the age of 60 years $(29,30,31)$. This is the first study that investigates the relationships between 
IGFBP-2, age and BMI in a longitudinal setting. Since in humans IGFBP-2 is inversely associated with BMI $(5,6$, $7,9)$ and in vitro studies in humans $(5,26)$ and animal studies (32) suggest that a change in IGFBP-2 induces changes in adipo- and lipogenesis, we investigated whether a decline in IGFBP-2 concentrations precedes a decline in BMI and therefore could be a marker of anorexia of aging. IGFBP-2 concentrations and BMI changed significantly over time and were negatively correlated. Although we demonstrated that a change in IGFBP-2 is associated with a parallel inverse change in BMI, it was difficult to show any direct causality. This might partly be due to the study population and missing data. Stored serum aliquots were not available for IGFBP-2 measurements for all participants around the ages of 55, 65 and 75 years. However, absent aliquots should be regarded as random events, and therefore, should not impact the overall findings of the study. Furthermore, volunteers participating in the BLSA are a rather selected, highly educated population. Due to the selection bias, it is difficult to make generalizations regarding the present observations. The strength of our study, however, is the longitudinal design with 20 years of serial measurements. And to our knowledge, we show for the first time in a longitudinal setting that IGFBP-2 concentrations not only change over time in proportion with BMI but also correlate positively with insulin sensitivity (when adjusted for BMI). IGFBP-2 might therefore serve as a potential marker for insulin sensitivity. Further research, however, is necessary to investigate the applicability of such a marker in daily practice.

In this study, low IGFBP-2 concentrations were initially predictive of all-cause and cardiovascular-related mortality. Although one might expect this observation since low IGFBP-2 concentrations are associated with the presence of metabolic syndrome, it is not, however, in keeping with earlier studies $(9,15)$. Given this obvious explanation that the relationship might be due to the inverse association of IGFBP-2 and parameters of the metabolic syndrome, we adjusted for insulin sensitivity which resulted in a positive association between IGFBP-2 and mortality. This means that in our population among subjects with the same insulin sensitivity, higher IGFBP-2 concentrations at baseline as well as in serial measurements were associated with an increased all-cause-related mortality. This is in agreement with our previous study in which we reported that high IGFBP-2 levels at baseline adjusted for insulin resistance were associated with an increased risk of 8-year all-cause mortality (9). Hu et al. also reported that in subjects older than 70 years, high
IGFBP-2 concentrations were associated with an increase in 6-year mortality (15).

Previous studies show that IGFBP-2 concentrations are high in patients with various types of cancers like colorectal cancer, gliomas, prostate cancer, breast cancer and lung cancer (reviewed by Yao et al.) (33). In our study, there were no data available on the presence of malignancy. In an effort to explain this possible association, we did investigate whether IGFBP-2 correlated with cancer-related mortality. Unfortunately, of the 176 deaths, 72 causes of death could not be ascertained and due to numerical problems, these analyses could only be performed without adjustment for insulin sensitivity. Therefore, no relationship was found between IGFBP-2 levels and cancer-related mortality.

The association between high IGFBP-2 levels and an increased mortality may also be explained by a poor nutritional status. IGFBP-2 levels are known to be extremely high in patients with anorexia nervosa (34) and low in patients with a rich protein diet (27). Adjustment for BMI did not influence the association with mortality. The presence of a selection bias may be another explanation for the relationship of high IGFBP-2 concentrations with increased mortality, namely that subjects with CVDs died earlier.

Unexpectedly, mean IGF-I concentrations increased with age in this population. This is in contrast to what has been found in most human studies of older adults (35). However, most of these studies were crosssectional with very few longitudinal studies describing the relationship between IGF-I and age. None of these studies had a follow-up time of 20 years. Although an overall slight decrease in mean IGF-I concentrations was found in these previous studies $(36,37,38)$, there was a large heterogeneity in course of IGF-I with some persons exhibiting a decrease in IGF-I concentrations, while in others IGF-I concentration remained constant or even increased over time $(36,38)$. The increase in IGF-I levels in this study might also reflect a survival bias. Sanders et al. determined that a steeper IGF-I trajectory slope and greater variability in trajectory rather than the actual IGF-I levels were more strongly predictive of mortality (36).

In conclusion, this is the first longitudinal study demonstrating that IGFBP-2 levels increase with age after the age of 50 years and evolve in parallel with insulin sensitivity. IGFBP-2 may therefore be a potential marker for insulin sensitivity. We further show that IGFBP-2 levels can predict mortality in this aging population. However, its predictive value for mortality can only be interpreted in relation to insulin sensitivity. After adjustment for 
insulin sensitivity, high IGFBP-2 levels are predictive of an increased mortality. Further studies are needed to examine whether high IGFBP-2 levels may reflect the presence of a poor nutritional state and/or neoplastic disease.

\section{Declaration of interest}

The authors declare that there is no conflict of interest that could be perceived as prejudicing the impartiality of this study.

\section{Funding}

This research was supported by the Intramural Research Program of the National Institutes of Health, National Institute on Aging, Baltimore, MD, USA.

\section{Author contribution statement}

All the authors contributed equally to the research and manuscript.

\section{Acknowledgements}

The authors are grateful to all participants who gave their time for this longitudinal research.

\section{References}

1 Toogood AA \& Shalet SM. Ageing and growth hormone status. Bailliere's Clinical Endocrinology and Metabolism 199812 281-296. (https://doi.org/10.1016/S0950-351X(98)80023-2)

2 Yau SW, Azar WJ, Sabin MA, Werther GA \& Russo VC. IGFBP-2 - taking the lead in growth, metabolism and cancer. Journal of Cell Communication and Signaling 20159 125-142. (https://doi. org/10.1007/s12079-015-0261-2)

3 Borst SE, Millard WJ \& Lowenthal DT. Growth hormone, exercise, and aging: the future of therapy for the frail elderly. Journal of the American Geriatrics Society 199442 528-535. (https://doi. org/10.1111/j.1532-5415.1994.tb04976.x)

4 Bartke A, Sun LY \& Longo V. Somatotropic signaling: trade-offs between growth, reproductive development, and longevity. Physiological Reviews 201393 571-598. (https://doi.org/10.1152/ physrev.00006.2012)

5 Wheatcroft SB, Kearney MT, Shah AM, Ezzat VA, Miell JR, Modo M, Williams SC, Cawthorn WP, Medina-Gomez G, Vidal-Puig A et al. IGF-binding protein-2 protects against the development of obesity and insulin resistance. Diabetes 200756 285-294. (https://doi. org/10.2337/db06-0436)

6 Hedbacker K, Birsoy K, Wysocki RW, Asilmaz E, Ahima RS, Farooqi IS \& Friedman JM. Antidiabetic effects of IGFBP2, a leptin-regulated gene. Cell Metabolism 201011 11-22. (https://doi.org/10.1016/j. cmet.2009.11.007)

7 Frystyk J, Skjaerbaek C, Vestbo E, Fisker S \& Orskov H. Circulating levels of free insulin-like growth factors in obese subjects: the impact of type 2 diabetes. Diabetes/Metabolism Research and Reviews 199915 314-322. (https://doi.org/10.1002/(SICI)15207560(199909/10) 15:5<314::AID-DMRR56>3.0.CO;2-E)

8 Heald AH, Kaushal K, Siddals KW, Rudenski AS, Anderson SG \& Gibson JM. Insulin-like growth factor binding protein-2 (IGFBP2) is a marker for the metabolic syndrome. Experimental and Clinical Endocrinology and Diabetes 2006114 371-376. (https://doi. org/10.1055/s-2006-924320)
9 van den Beld AW, Blum WF, Brugts MP, Janssen JA, Grobbee DE \& Lamberts SW. High IGFBP2 levels are not only associated with a better metabolic risk profile but also with increased mortality in elderly men. European Journal of Endocrinology 2012167 111-117. (https://doi.org/10.1530/EJE-12-0160)

10 Fazeli PK, Lawson EA, Prabhakaran R, Miller KK, Donoho DA, Clemmons DR, Herzog DB, Misra M \& Klibanski A. Effects of recombinant human growth hormone in anorexia nervosa: a randomized, placebo-controlled study. Journal of Clinical Endocrinology and Metabolism 201095 4889-4897. (https://doi. org/10.1210/jc.2010-0493)

11 Pickard A \& McCance DJ. IGF-binding protein 2: Oncogene of Tumor Suppresor?. Frontiers in Endocrinology 20156 25. (https://doi. org/10.3389/fendo.2015.00025)

12 Liou JM, Shun CT, Liang JT, Chiu HM, Chen MJ, Chen CC, Wang HP, Wu MS \& Lin JT. Plasma insulin-like growth factor-binding protein-2 levels as diagnostic and prognostic biomarker of colorectal cancer. Journal of Clinical Endocrinology and Metabolism 201095 1717-1725. (https://doi.org/10.1210/jc.2009-2668)

13 Baron-Hay S, Boyle F, Ferrier A \& Scott C. Elevated serum insulin-like growth factor binding protein-2 as a prognostic marker in patients with ovarian cancer. Clinical Cancer Research 200410 1796-1806. (https://doi.org/10.1158/1078-0432.CCR-0672-2)

14 Probst-Hensch NM, Steiner JH, Schraml P, Varga Z, Zurrer-Hardi U, Storz M, Korol D, Fehr MK, Fink D, Pestalozzi BC et al. IGFBP2 and IGFBP3 protein expressions in human breast cancer: association with hormonal factors and obesity. Clinical Cancer Research 201016 1025-1032. (https://doi.org/10.1158/1078-0432.CCR-09-0957)

15 Hu D, Pawlikowska L, Kanaya A, Hsueh WC, Colbert L, Newman AB, Satterfield S, Rosen C, Cummings SR, Harris TB et al. Serum insulinlike growth factor-1 binding proteins 1 and 2 and mortality in older adults: the Health, Aging, and Body Composition Study. Journal of the American Geriatrics Society 200957 1213-1218. (https://doi. org/10.1111/j.1532-5415.2009.02318.x)

16 Shock NW, Greulich RC, Costa PT Jr, Andres R, Lakatta EG, Arenberg D \& Tobin JD. Normal Human Aging. Washington D.C.: U.S. Govt. Printing office, (1984 edn.). the Baltimore longitudinal Study of aging 84-2450 Ed NIo Health.

17 Lissner L, Andres R, Muller DC \& Shimokata H. Body weight variability in men: metabolic rate, health and longevity. International Journal of Obesity 199014 373-383.

18 Theodorakis MJ, Carlson O, Muller DC \& Egan JM. Elevated plasma glucose-dependent insulinotropic polypeptide associates with hyperinsulinemia in impaired glucose tolerance. Diabetes Care 2004 27 1692-1698. (https://doi.org/10.2337/diacare.27.7.1692)

19 Matsuda M \& DeFronzo RA. Insulin sensitivity indices obtained from oral glucose tolerance testing: comparison with the euglycemic insulin clamp. Diabetes Care 199922 1462-1470. (https://doi. org/10.2337/diacare.22.9.1462)

20 Verbeke G, Fieuws S, Molenberghs G \& Davidian M. The analysis of multivariate longitudinal data: a review. Statistical Methods in Medical Research 201726 112. (https://doi.org/10.1177/0962280214539862)

21 Rizopoulos D \& Takkenberg JJ. Tools \& techniques - statistics: dealing with time-varying covariates in survival analysis - joint models versus Cox models. EuroIntervention 201410 285-288. (https://doi. org/10.4244/EIJV10I2A47)

22 Blum WF \& Breier BH. Radioimmunoassays for IGFs and IGFBPs. Growth Regulation 19944 (Supplement 1) 11-19.

23 Jones JI, Doerr ME \& Clemmons DR. Cell migration: interactions among integrins, IGFs and IGFBPs. Progress in Growth Factor Research 19956 319-327. (https://doi.org/10.1016/0955-2235(95)00015-1)

24 Li Z, Miard S, Laplante M, Sonenberg N \& Picard F. Insulin stimulates IGFBP-2 expression in 3T3-L1 adipocytes through the PI3K/mTOR pathway. Molecular and Cellular Endocrinology 2012358 63-68. (https://doi.org/10.1016/j.mce.2012.02.022) 
25 Asilmaz E, Cohen P, Miyazaki M, Dobrzyn P, Ueki K, Fayzikhodjaeva G, Soukas AA, Kahn CR, Ntambi JM, Socci ND et al. Site and mechanism of leptin action in a rodent form of congenital lipodystrophy. Journal of Clinical Investigation 2004113 414-424. (https://doi.org/10.1172/JCI200419511)

26 Yau SW, Henry BA, Russo VC, McConell GK, Clarke IJ, Werther GA $\&$ Sabin MA. Leptin enhances insulin sensitivity by direct and sympathetic nervous system regulation of muscle IGFBP-2 expression: evidence from nonrodent models. Endocrinology 2014 155 2133-2143. (https://doi.org/10.1210/en.2013-2099)

27 Young NJ, Metcalfe C, Gunnell D, Rowlands MA, Lane JA, Gilbert R, Avery KN, Davis M, Neal DE, Hamdy FC et al. A crosssectional analysis of the association between diet and insulinlike growth factor (IGF)-I, IGF-II, IGF-binding protein (IGFBP)-2, And IGFBP-3 in men in the United Kingdom. Cancer Causes and Control 201223 907-917. (https://doi.org/10.1007/s10552-0129961-6)

28 Closa-Monasterolo R, Ferre N, Luque V, Zaragoza-Jordana M, Grote V, Weber M, Koletzko B, Socha P, Gruszfeld D, Janas R et al. Sex differences in the endocrine system in response to protein intake early in life. American Journal of Clinical Nutrition 201194 1920S-1927S. (https://doi.org/10.3945/ajcn.110.001123)

29 Blum WF, Horn N, Kratzsch J, Jorgensen JO, Juul A, Teale D, Mohnike K \& Ranke MB. Clinical studies of IGFBP-2 by radioimmunoassay. Growth Regulation 19933 100-104.

30 Mattsson A, Svensson D, Schuett B, Osterziel KJ \& Ranke MB. Multidimensional reference regions for IGF-I, IGFBP-2 and IGFBP-3 concentrations in serum of healthy adults. Growth Hormone and IGF Research 200818 506-516. (https://doi.org/10.1016/j. ghir.2008.04.005)

31 van den Beld AW, Blum WF, Pols HA, Grobbee DE \& Lamberts SW. Serum insulin-like growth factor binding protein-2 levels as an indicator of functional ability in elderly men. European Journal of Endocrinology 2003148 627-634. (https://doi.org/10.1530/ eje.0.1480627)

32 Xi G, Solum MA, Wai C, Maile LA, Rosen CJ \& Clemmons DR. The heparin-binding domains of IGFBP-2 mediate its inhibitory effect on preadipocyte differentiation and fat development in male mice. Endocrinology 2013154 4146-4157. (https://doi.org/10.1210/ en.2013-1236)

33 Yao X, Sun S, Zhou X, Guo W \& Zhang L. IGF-binding protein 2 is a candidate target of therapeutic potential in cancer. Tumour Biology 201637 1451-1459. (https://doi.org/10.1007/s13277-015-4561-1)

34 Counts DR, Gwirtsman H, Carlsson LM, Lesem M \& Cutler GB Jr. The effect of anorexia nervosa and refeeding on growth hormonebinding protein, the insulin-like growth factors (IGFs), and the IGF-binding proteins. Journal of Clinical Endocrinology and Metabolism $199275762-767$.

35 Di Somma C, Brunelli V, Savanelli MC, Scarano E, Savastano S, Lombardi G \& Colao A. Somatopause: state of the art. Minerva Endocrinol 201136 243-255.

36 Sanders JL, Guo W, O'Meara ES, Kaplan RC, Pollak MN, Bartz TM, Newman AB, Fried LP \& Cappola AR. Trajectories of IGF-I predict mortality in older adults: the cardiovascular Health Study. Journals of Gerontology: Series A, Biological Sciences and Medical Sciences 201873 953-959. (https://doi.org/10.1093/gerona/glx143)

37 Bann D, Holly JMP, Lashen H, Hardy R, Adams J, Kuh D, Ong KK $\&$ Ben-Shlomo Y. Changes in insulin-like growth factor-I and -II associated with fat but not lean mass in early old age. Obesity 2015 23 692-698. (https://doi.org/10.1002/oby.21002)

38 Kaplan RC, Buzkova P, Cappola AR, Strickler HD, McGinn AP, Mercer LD, Arnold AM, Pollak MN \& Newman AB. Decline in circulating insulin-like growth factors and mortality in older adults: cardiovascular health study all-stars study. Journal of Clinical Endocrinology and Metabolism 201297 1970-1976. (https://doi. org/10.1210/jc.2011-2967)

Received 15 May 2018

Revised version received 11 November 2018

Accepted 22 November 2018 